\title{
A Carga Tributária Efetiva sobre o Trabalho no Brasil: Nivel, Distribuição e Composição
}

\section{Tax Burden on Labor in Brazil: Level, Distribution and Structure}

\author{
José Ricardo Bezerra Nogueira* \\ Rozane Bezerra de Siqueira** \\ Pollyana Jucá Santana*** \\ Horacio Leuy**** \\ Evaldo Santana de Souza****
}

Resumo: Este artigo analisa o nível, a distribuição e a composição da carga tributária sobre o trabalho no Brasil, mostrando quantos e que tipos de trabalhadores são afetados por diferentes níveis de alíquotas efetivas. Os resultados mostram que a cunha fiscal média representa em torno de um quarto do custo total do trabalho, porém, há variações significativas entre subgrupos de trabalhadores. Por exemplo, a alíquota tributária efetiva para um trabalhador que recebe um salário mínimo e tem três ou mais filhos é igual a pouco mais de um terço da alíquota para um trabalhador com rendimento acima de 30 salários mínimos. O estudo mostra também que, comparada às cunhas fiscais dos países da União Europeia e da OCDE, a carga brasileira sobre o trabalho é uma das mais baixas, principalmente para os salários mais altos.

Palavras-chave: Tributação do trabalho. Alíquotas efetivas. Cunha fiscal.

Abstract: This paper investigates the level, distribution and structure of the tax burden on labor in Brazil, showing how many and what types of workers are affected by different levels of taxation. The results show a significant variation in the level and composition of the tax burden among subgroups of workers. For example, the effective tax rate for a worker earning the legal minimum wage and

* Professor do Departamento de Economia da Universidade Federal de Pernambuco (UFPE). E-mail: jrbnogueira@yahoo.com.br

** Professora do Departamento de Economia da Universidade Federal de Pernambuco (UFPE). E-mail: rozane_siqueira@yahoo.com.br

*** Doutoranda do Programa de Pós-Graduação em Economia da Universidade Federal de Pernambuco (UFPE). E-mail: pollyanajs@hotmail.com

**** Pesquisador do Institute for Social and Economic Research (ISER) da University of Essex, Colchester, United Kingdom, e do European Centre for Social Welfare Policy Research, Vienna, Austria. E-mail: hlevy@essex.ac.uk

****** Professor do Departamento de Ciências Contábeis da Universidade Federal de Pernambuco (UFPE).E-mail: ess@ufpe.br 
having three or more children is little more than a third of the tax rate for a worker with earnings above thirty minimum wages. The study also shows that, compared to the European Union and OCDE countries, the Brazilian tax wedge on labor is one of the lowest, particularly for higher wages.

Keywords: Taxation of labor. Effective rates. Tax wedge.

JEL Classification: $\mathrm{H} 2 ; \mathrm{H} 24$.

\section{$1 \operatorname{lntrodução~}$}

Há uma percepção geral de que a tributação do trabalho no Brasil é particularmente elevada, sendo considerada um dos principais componentes do chamado "custo Brasil". De fato, alguns analistas defendem que o peso dos tributos sobre os salários no Brasil chega a ser maior do que em países muito ricos ou industrializados. ${ }^{1}$ Refletindo preocupação com esse peso, em 2008 o Poder Executivo encaminhou ao Congresso Nacional uma proposta de reforma tributária que inclui uma medida de desoneração da folha salarial das empresas. No mesmo sentido, desde 2011, o governo eliminou, provisoriamente, para alguns setores específicos, a contribuição previdenciária patronal que incide sobre a folha, substituindo-a por uma contribuição sobre o faturamento das empresas. ${ }^{2}$ Argumenta-se que tais medidas contribuirão de forma relevante para estimular o emprego formal e aumentar a competitividade das empresas nacionais (BRASIL, 2008).

Todavia, do nosso conhecimento, não há estudos para o Brasil que analisem a carga tributária sobre o trabalho de forma ampla e metodologicamente consistente com as estimativas internacionais disponíveis. Ademais, os efeitos da tributação sobre o mercado de trabalho dependem não apenas do nível da carga tributária, mas também de sua composição e distribuição entre os diferentes subgrupos de trabalhadores. Tal detalhamento também é necessário para se investigar o perfil distributivo dos tributos sobre o trabalho, questão que tem sido negligenciada nas discussões sobre a desoneração da folha salarial.

As estimativas existentes da carga tributária sobre o trabalho no Brasil, em geral, calculam a tributação sobre o trabalho de um empregado que recebe o salário mínimo legal (sem especificação de outra característica do empregado). ${ }^{3}$ Apenas dois estudos adotam uma abordagem mais abrangente. O primeiro é de Araújo Neto e Sampaio de Sousa (2003), que usa dados agregados da arrecadação

\footnotetext{
1 Ver, por exemplo, o trabalho do Instituto Brasileiro de Planejamento Tributário (IBPT, 2006).

2 Mais recentemente, através da Medida Provisória 563/2012, o governo ampliou o número de empresas (ou produtos) beneficiadas pela eliminação da contribuição previdenciária patronal. Pela medida, a vigência da desoneração é até 2014.

3 Um exemplo é Dieese (1997).
} 
tributária e das contas nacionais para obter uma única alíquota tributária efetiva sobre a renda do trabalho, representando uma média nacional. O segundo estudo é de Paes e Bugarin (2006), que estima alíquotas tributárias efetivas para diferentes classes de renda a partir de dados agregados, o que envolve importantes hipóteses simplificadoras em relação à incidência das contribuições previdenciárias e do imposto de renda. ${ }^{4}$

Estudos para outros países, baseados em microdados, indicam que a carga tributária efetiva sobre o trabalho pode diferir significativamente entre subgrupos da população, dependendo não apenas do nível salarial, mas também das características demográficas das famílias (IMMERVOLL, 2004; CLARK, 2004). Assim, uma única alíquota tributária calculada com base em dados agregados pode ser um indicador bastante equivocado da carga tributária efetiva com que se depara um grande número de trabalhadores. Mesmo uma abordagem baseada em um conjunto de trabalhadores "típicos" é limitada, uma vez que não é capaz de captar, nas proporções devidas a heterogeneidade da população, bem como a complexidade do sistema de tributos e benefícios (HEADY, 2004). Portanto, cálculos de alíquotas tributárias efetivas utilizando microdados podem ter um papel importante em complementar estimativas baseadas em dados agregados ou em "indivíduos típicos". Em particular, podem tornar mais consistentes as comparações internacionais, oferecendo um detalhamento relevante para decisões de políticas públicas.

O objetivo deste artigo é analisar a distribuição e a composição da carga tributária efetiva sobre o trabalho no Brasil, utilizando uma amostra de microdados nacionalmente representativa e um modelo de microssimulação de tributos e benefícios. Mais especificamente, o estudo procura mostrar quantos e que tipos de trabalhadores se deparam com diferentes níveis de alíquotas tributárias efetivas e quais os fatores que determinam essas alíquotas.

O artigo está organizado da seguinte forma: a seção 2 identifica os tributos e os benefícios que compõem a cunha fiscal sobre o trabalho no Brasil; a seção 3 descreve os dados e o modelo de microssimulação usados para calcular os tributos e os benefícios para cada trabalhador; a seção 4 apresenta estimativas da distribuição e da composição da carga tributária efetiva sobre o trabalho no Brasil; a

4 Por exemplo, Paes e Bugarin (2006) supõem que as contribuições previdenciárias incidem igualmente sobre todas as classes de renda (ignorando, inclusive, a presença de trabalhadores informais e autônomos). Além disso, esse estudo não leva em conta os benefícios monetários que alguns trabalhadores formais recebem do governo.

5 Cabe mencionar ainda o trabalho do IBPT (2006), que calcula a carga tributária para diferentes níveis de salário. Porém, nesse estudo, as alíquotas tributárias para o Brasil estão fortemente superestimadas, uma vez que as contribuições dos empregadores foram incluídas no numerador da fórmula de cálculo da carga tributária, mas não foram incluídas no denominador. Isso representa um equívoco conceitual e diverge do procedimento internacional. Além disso, o estudo não considerou os benefícios monetários, pagos pelo governo, recebidos por alguns empregados formais. 
seção 5 compara os resultados para o Brasil com estimativas para outros países; e a seção 6 apresenta os comentários finais.

\section{Componentes da Carga Tributária Efetiva sobre o Trabalho no Brasil}

A carga tributária efetiva sobre o trabalho é aqui mensurada como a diferença entre o custo do trabalho para o empregador e o correspondente rendimento líquido que o empregado "leva para casa", como proporção do custo de trabalho. Essa medida, usualmente chamada de "cunha fiscal" sobre o trabalho, é a forma normalmente utilizada para expressar a carga tributária quando o objetivo é entender como a política fiscal influencia (ou pode influenciar) as decisões das empresas e dos indivíduos no mercado de trabalho.

O custo do trabalho é determinado como a soma dos rendimentos salariais brutos do empregado, da contribuição previdenciária do empregador e dos demais tributos que incidem sobre a folha salarial. Por sua vez, o que o empregado "leva para casa" é o seu rendimento salarial bruto, menos sua contribuição previdenciária juntamente com o imposto de renda, mais os benefícios monetários recebidos. Portanto, a cunha fiscal sobre o trabalho é dada pela soma das contribuições previdenciárias do empregado e do empregador juntamente com os outros tributos sobre a folha, mais o imposto de renda da pessoa física, menos os benefícios, como percentagem do custo do trabalho. Deve-se reconhecer que essa medida pode não refletir todos os custos trabalhistas com os quais se deparam os empregadores. Todavia, essa tem sido a definição de cunha fiscal de uso generalizado internacionalmente (ORGANIZAÇÃO PARA A COOPERAÇÃO E DESENVOLVIMENTO ECONÓMICO - OCDE, 2010), o que facilita a realização de comparações.

No caso do Brasil, o rendimento salarial bruto do trabalhador inclui, além do salário recebido mensalmente, o $13^{\circ}$ salário, o adicional de férias e o Fundo de Garantia do Tempo de Serviço (FGTS). Cabe notar que o FGTS é uma espécie de conta poupança aberta em nome do empregado pelo empregador, e considerá-lo como parte dos salários significa supor que o custo dessa poupança para o empregador se reverte integralmente em benefício do empregado. ${ }^{6}$ Pode-se esperar, no entanto, que a poupança forçada do FGTS tenha um valor menor para os trabalhadores do que o dinheiro depositado pelas empresas. Todavia, na ausência de uma estimativa do valor que os empregados atribuem ao FGTS, utilizaremos aqui o valor do depósito como proxy do benefício recebido pelo trabalhador.

No cálculo do custo do trabalho, além da contribuição do empregador ao Instituto Nacional de Seguridade Social (INSS) e do FGTS, as seguintes contri-

6 Ou, como coloca Fernandes e Menezes-Filho (2002), supõe-se que os trabalhadores são indiferentes entre o FGTS e receber em mãos o dinheiro que as empresas depositam nesse fundo. 
buições que incidem sobre a folha de salários das empresas são consideradas: as contribuições ao sistema S e ao Instituto Nacional de Colonização e Reforma Agrária (Incra), o salário educação e o seguro de acidentes de trabalho (SAT). ${ }^{7}$ Finalmente, os benefícios recebidos por empregados, e incluídos no presente estudo, são as transferências monetárias pagas pelo governo condicionadas ao trabalho formal, a saber: o abono salarial e o salário família. ${ }^{8}$

\section{Modelo e Dados}

O cálculo das alíquotas tributárias efetivas é realizado a partir de uma amostra de microdados representativa da população brasileira, a pesquisa nacional por amostra de domicílios (PNAD). No entanto, como as informações sobre os tributos e os benefícios que compõem a cunha fiscal sobre o trabalho não estão presentes diretamente na PNAD, esses componentes são calculados usando um modelo de microssimulação. Da mesma forma, o $13^{\circ}$ salário e o adicional de férias dos trabalhadores também precisam ser calculados usando o modelo de microssimulação.

Um modelo de microssimulação de tributos e benefícios (conhecido na literatura internacional como tax-benefit microsimulation model) é um programa computacional que aplica as regras da legislação fiscal e previdenciária para calcular os tributos devidos e os benefícios recebidos por cada indivíduo ou família em uma amostra nacionalmente representativa da população. O funcionamento de um modelo de microssimulação pode ser descrito da seguinte forma. As regras do sistema fiscal vigente (por exemplo, as regras do imposto de renda das pessoas físicas) são aplicadas sobre os indivíduos contidos na base de microdados do modelo. Para cada indivíduo, é utilizada informação sobre renda e características pessoais e familiares na realização da aritmética necessária para calcular os tributos devidos e os benefícios recebidos.

O modelo de microssimulação utilizado na realização do presente estudo é o Brazilian Household Microsimulation System (BRAHMS). O BRAHMS calcula cada tributo e benefício na ordem legal, de forma que as interações entre os diferentes elementos do sistema são levadas em conta (por exemplo, o fato da contribuição previdenciária do empregado ser dedutível da base de cálculo do imposto de renda). Da mesma forma, qualquer dedução tributária e outras provisões legais que dependem da renda, situação familiar ou outras características presentes nos

$7 \quad$ As alíquotas sobre a folha salarial vigentes em 2009 e utilizadas neste estudo são as seguintes: $20 \%$ da contribuição patronal ao INSS; 8\% do FGTS; 3,3\% de contribuições ao sistema S (Sesi/Sesc, Sebrae, Senai/Senac) e Incra; $2,5 \%$ do salário educação; e $2 \%$ de SAT (média).

8 O abono salarial consiste do pagamento anual de um salário mínimo a empregados com salários inferiores a dois salários mínimos e registrados no PIS. O salário família é pago mensalmente a empregados com salário até um dado limite ( $\mathrm{R} \$ 752,12$, em 2009) e com filhos com idade inferior a 14 anos. Em 2009, o valor desse benefício por criança era de $R \$ 25,66$ para salários até $R \$$ 500,40 e de $R \$ 18,08$ para salários até $R \$ 752,12$. 
microdados da PNAD são consideradas nas simulações. A versão do BRAHMS utilizada neste estudo utiliza como base de microdados a PNAD referente ao ano de 2009 e simula as legislações dos tributos e benefícios sociais vigentes nesse ano. ${ }^{9}$

Os cálculos do presente estudo são aplicados a um subgrupo da população trabalhadora, incluindo apenas empregados formais - exceto servidores públicos estatutários e militares - com idade entre 18 e 59 anos. O trabalhador por conta própria é excluído devido à ausência de informação na base de microdados da PNAD sobre a participação relativa do trabalho e do capital na renda desse tipo de trabalhador. Por sua vez, a exclusão de funcionários públicos evita problemas relacionados à imputação da contribuição previdenciária do empregador. Além disso, as estimativas internacionais da cunha fiscal sobre o trabalho, em geral, também adotam esse procedimento, concentrando-se em empregados formais do setor privado (IMMERVOLL, 2004), o que facilita as comparações.

Cabe lembrar que o Imposto de Renda da Pessoa Física (IRPF) é calculado sobre a soma de todos os rendimentos tributáveis, de forma que não é simples obter o imposto pago apenas sobre a renda do trabalho nos casos em que os indivíduos têm renda de mais de uma fonte. Seguindo Immervoll (2004) e Clark (2004), a abordagem adotada no presente estudo é calcular, para cada contribuinte individualmente, a alíquota média do imposto de renda que incide sobre sua renda tributável como um todo e, então, supor que essa alíquota se aplica uniformemente a todos os componentes da renda tributável.

O IRPF foi calculado sob a hipótese de que os indivíduos maximizam a renda disponível (pós-imposto), escolhendo o tipo de declaração, simples ou completa, que minimiza o montante do imposto a ser pago. Além da dedução padrão (no caso da declaração simples), as deduções da base de cálculo do IRPF consideradas na simulação são: a dedução por dependente do contribuinte, a dedução da contribuição previdenciária oficial, a dedução de despesas com instrução e a dedução de despesas médicas.

Uma vez que a PNAD não fornece dados que permitam calcular as despesas das famílias com educação e com saúde, as deduções dessas despesas da base do IRPF tiveram de ser imputadas. No caso da dedução de despesas com instrução, atribuiu-se o valor máximo permitido pela legislação do IRPF (uma vez que esse limite é relativamente baixo) para cada pessoa do domicílio (declarante ou dependente) que frequenta escola ou universidade da rede privada. Por sua vez, as deduções de despesas médicas (que não são legalmente limitadas) foram imputadas a partir dos microdados da Pesquisa de Orçamentos Familiares (POF) 2008-2009.10

$9 \quad$ A PNAD 2009 era a última disponível no período de realização do presente trabalho.

10 Na POF 2008-09, foram calculados, para cada décimo de rendimento monetária domiciliar per capita, os valores médios de gastos com saúde dedutíveis do imposto de renda da pessoa física. Esses valores foram, então, imputados para os correspondentes décimos de renda monetária domiciliar per capita no banco baseado na PNAD 2009. 
Os resultados gerados pelo BRAHMS passam por um processo de validação que envolve conferir se os resultados agregados produzidos pelo modelo são consistentes com as estatísticas oficiais disponíveis. Quando necessário, o modelo é calibrado de forma que os agregados gerados pelas simulações se aproximem dos dados agregados oficiais. Em geral, as estimativas geradas pelo modelo se conformam razoavelmente bem com os dados oficiais e as diferenças observadas, devidas principalmente a limitações de dados e a hipóteses adotadas estão de acordo com aquelas geralmente encontradas em modelos de outros países. ${ }^{11}$

\section{Resultados}

Nesta seção são apresentados os resultados das simulações das alíquotas efetivas para o Brasil e uma breve análise comparativa com outros países.

\subsection{Alíquotas Tributárias Efetivas sobre o Trabalho: Distribuição e Composição}

A distribuição das alíquotas efetivas sobre o trabalho é mostrada na Tabela 1. Nota-se que, mesmo considerando apenas os intervalos de alíquota que compreendem mais de $7 \%$ dos trabalhadores, a diferença entre as alíquotas efetivas pode alcançar até 15 pontos percentuais. Assim, embora haja uma grande concentração de alíquotas efetivas em torno da média, uma única alíquota tributária média (ou agregada) derivada usando-se dados agregados é uma representação pobre da cunha fiscal efetiva para grande parte dos assalariados.

Essa diferenciação de alíquotas efetivas ocorre essencialmente entre trabalhadores com diferentes níveis salariais e/ou com um número diferente de dependentes. Isso é evidenciado nas Tabelas 2 e 3. A Tabela 2 apresenta estimativas da cunha fiscal média para diferentes classes de renda salarial, desagregando os resultados de forma a isolar a influência das contribuições pagas pelo empregador, da contribuição previdenciária do empregado, do IRPF e dos benefícios sociais monetários recebidos por alguns empregados. Por sua vez, a Tabela 3 mostra as alíquotas efetivas por classe de renda salarial e por número de filhos até 14 anos de idade. Nessas tabelas, a renda salarial é expressa em termos do salário mínimo legal (SM) vigente em 2009 , que era de $\mathrm{R} \$ 465,00$ por mês.

11 Para mais detalhes sobre as simulações realizadas pelo BRAHMS e a validação de seus resultados, ver Immervoll et al. (2009) e Levy et al. (2010). 
Tabela 1 - Distribuição das alíquotas tributárias efetivas médias sobre o trabalho no Brasil

\begin{tabular}{lcc}
\hline $\begin{array}{l}\text { Aliquota tributária } \\
\text { efetiva (\%) }\end{array}$ & $\begin{array}{c}\text { Número de } \\
\text { trabalhadores }\end{array}$ & $\begin{array}{c}\text { Percentagem de } \\
\text { trabalhadores (\%) }\end{array}$ \\
\hline Até 0 & 11.940 & 0,04 \\
$0--\mid 5$ & 37.109 & 0,12 \\
$5--\mid 10$ & 131.941 & 0,41 \\
$10--\mid 15$ & 465.826 & 1,46 \\
$15--\mid 20$ & 3.351 .299 & 10,48 \\
$20--\mid 25$ & 7.200 .298 & 22,53 \\
$25--\mid 30$ & 17.822 .410 & 55,76 \\
$30--\mid 35$ & 2.351 .320 & 7,36 \\
$35--\mid 40$ & 527.891 & 1,65 \\
$40--\mid 45$ & 55.778 & 0,17 \\
$45--\mid 50$ & 4.217 & 0,01 \\
$>50$ & 4.119 & 0,01 \\
Total & 31.964 .148 & 100,0 \\
Mediana (\%) & 26,6 & \\
Média (\%) & 25,5 & \\
Desvio padrão & 4,6 & \\
\hline
\end{tabular}

Fonte: Elaborada pelos autores.

Tabela 2 - Alíquotas tributárias efetivas médias por classe de renda salarial

\begin{tabular}{|c|c|c|c|c|c|c|c|}
\hline $\begin{array}{l}\text { Renda } \\
\text { salarial } \\
\text { mensal } \\
\text { (em SM) }\end{array}$ & $\begin{array}{l}\text { Renda mé- } \\
\text { dia mensal } \\
\text { (R\$) }\end{array}$ & $\begin{array}{c}\text { Empre- } \\
\text { gados } \\
(\%)\end{array}$ & $\begin{array}{c}\text { Alíquota } \\
\text { efetiva } \\
\text { total } \\
\text { (\%) }\end{array}$ & $\begin{array}{l}\text { Contribui- } \\
\text { ção empre- } \\
\text {-gador* } \\
\text { (\%) }\end{array}$ & $\begin{array}{l}\text { INSS } \\
\text { empre- } \\
\text {-gado } \\
\text { (\%) }\end{array}$ & $\begin{array}{c}\text { IRPF } \\
\text { (\%) }\end{array}$ & $\begin{array}{l}\text { Benefi- } \\
\text {-cios** } \\
(\%)\end{array}$ \\
\hline $1-\mid 1,5$ & 532 & 46,0 & 22,8 & 19,6 & 6,0 & 0,0 & $-2,9$ \\
\hline $1,5-\mid 2$ & 826 & 19,3 & 25,4 & 20,3 & 6,1 & 0,2 & $-1,3$ \\
\hline $2-13$ & 1.119 & 16,2 & 27,4 & 20,5 & 6,6 & 0,3 & 0,0 \\
\hline $3-14$ & 1.570 & 7,2 & 29,1 & 20,6 & 7,9 & 0,7 & 0,0 \\
\hline $4-\mid 5$ & 2.057 & 4,0 & 30,1 & 20,7 & 8,1 & 1,3 & 0,0 \\
\hline $5-16$ & 2.513 & 1,7 & 31,1 & 20,6 & 8,1 & 2,3 & 0,0 \\
\hline $6-18$ & 3.121 & 2,5 & 31,9 & 20,7 & 7,5 & 3,8 & 0,0 \\
\hline $8-\mid 10$ & 4.130 & 1,1 & 32,6 & 20,7 & 5,7 & 6,2 & 0,0 \\
\hline $10-\mid 15$ & 5.432 & 1,2 & 34,3 & 20,7 & 4,4 & 9,2 & 0,0 \\
\hline $15-20$ & 7.797 & 0,5 & 36,7 & 20,7 & 3,0 & 13,0 & 0,0 \\
\hline $20-\mid 30$ & 10.778 & 0,2 & 38,2 & 20,7 & 2,2 & 15,4 & 0,0 \\
\hline$>30$ & 21.841 & 0,1 & 40,0 & 20,7 & 1,3 & 18,1 & 0,0 \\
\hline Total & 1.096 & 100,0 & 25,5 & 20,1 & 6,4 & 0,6 & $-1,6$ \\
\hline
\end{tabular}

Fonte: Elaborada pelos autores.

Notas: * Contribuição patronal para o INSS e as outras contribuições sobre a folha salarial; * * Abono salarial e salário família. 
Tabela 3 - Alíquotas tributárias efetivas sobre o trabalho por classe de renda e número de filhos (\%)

\begin{tabular}{lcccc}
\hline \multirow{2}{*}{$\begin{array}{l}\text { Renda salarial mensal } \\
\text { (em SM*) }\end{array}$} & $\mathbf{5}$ & $\mathbf{1}$ & $\mathbf{2}$ & $\mathbf{3}$ ou + \\
\cline { 2 - 5 } & 24,6 & 22,5 & 19,4 & 14,5 \\
$1-\mid 1,5$ & 25,7 & 25,4 & 24,8 & 22,7 \\
$1,5-\mid 2$ & 27,4 & 27,5 & 27,4 & 27,3 \\
$2-\mid 3$ & 29,2 & 29,0 & 28,9 & 28,7 \\
$3-\mid 4$ & 30,1 & 30,1 & 29,7 & 29,5 \\
$4-\mid 5$ & 31,3 & 31,2 & 30,5 & 30,4 \\
$5-\mid 6$ & 32,2 & 31,8 & 31,3 & 31,2 \\
$6-\mid 8$ & 32,8 & 32,5 & 32,1 & 31,2 \\
$8-\mid 10$ & 34,5 & 34,2 & 33,9 & 33,0 \\
$10-\mid 15$ & 36,8 & 36,6 & 36,4 & 35,8 \\
$15-\mid 20$ & 38,3 & 38,0 & 37,9 & - \\
$20-\mid 30$ & 40,0 & 39,9 & 39,6 & - \\
$>30$ & & &
\end{tabular}

Fonte: Elaborada pelos autores.

Nota: * Salário mínimo legal vigente em 2009, igual a $\mathrm{R} \$ 465,00$.

A Tabela 2 mostra que a cunha fiscal média sobre o trabalho aumenta consideravelmente com a renda salarial, passando de $22,8 \%$, para salários de até 1,5 salário mínimo, para 40,0\%, para salários acima de 30 salários mínimos. Observe-se, no entanto, que há forte concentração dos empregados nas classes salariais mais baixas: $65,3 \%$ com até dois salários mínimos e $81,5 \%$ com até três salários mínimos. Por outro lado, a Tabela 3 mostra que, mesmo dentro das duas primeiras classes salariais, há uma variação significativa da cunha fiscal, associada ao número de filhos (até 14 anos) dos empregados. Para salários de até 1,5 salário mínimo, a cunha fiscal de $24,6 \%$ para o empregado sem filho cai para $19,4 \%$, quando o empregado tem dois filhos, e para 14,5\% quando o empregado tem três ou mais filhos, refletindo o efeito do salário família. ${ }^{12}$ Nota-se ainda que a carga tributária efetiva para o empregado com três ou mais filhos e com salário igual ao mínimo legal corresponde a 36\% da carga tributária para o empregado com salário acima de 30 salários mínimos (independentemente do número de filhos).

A Tabela 2 mostra ainda que a composição da cunha fiscal também varia significativamente com o nível salarial. As contribuições do empregador representam mais de 80,0\% da cunha fiscal média para salários de até dois salários mínimos, caindo para $51,7 \%$ quando o salário excede 30 salários mínimos. Em contraste, o IRPF tem peso virtualmente nulo nas classes salariais mais baixas, mas representa em média $45,2 \%$ da cunha fiscal para salários acima de 30 salários míni-

12 Embora de forma menos significativa, o número de filhos do empregado também contribui para reduzir a cunha fiscal sobre o trabalho via deduções do imposto de renda. 
mos. ${ }^{13}$ Cabe esclarecer que a alíquota efetiva média de contribuição patronal é levemente menor na classe salarial mais baixa devido à presença do empregado doméstico, que se beneficia de uma alíquota legal reduzida. ${ }^{14}$ Quanto à contribuição do empregado, o perfil de variação mostrado na Tabela 2 reflete o efeito das alíquotas legais progressivas e do teto de contribuição, de forma que a alíquota efetiva primeiro cresce com o salário e depois decresce. Por fim, observa-se que os benefícios do abono salarial e do salário família reduzem em 2,9\% pontos percentuais, em média, a cunha fiscal para salários próximos do salário mínimo. Nota-se que isso representa quase metade da alíquota efetiva média da contribuição previdenciária do empregado na classe de renda mais baixa.

\subsection{Comparação Internacional}

Esta seção procura investigar como as alíquotas tributárias efetivas sobre o trabalho no Brasil se comparam com as de outros países. Para isso, comparamos nossas estimativas para o Brasil com aquelas obtidas por Immervoll (2004) para 14 países da União Europeia e também com estimativas da OCDE (2011).

Immervoll (2004) estima alíquotas efetivas utilizando um modelo integrado de microssimulação de tributos e benefícios para países da União Europeia (EUROMOD), bem como outros procedimentos metodológicos consistentes com os adotados no presente estudo. A Tabela 4 mostra as alíquotas tributárias efetivas medianas no Brasil e nos 14 países analisados por Immervoll, para empregados agrupados em décimos de acordo com o custo do trabalho (rendimento bruto do trabalho mais contribuições do empregador).

Tabela 4 - Alíquotas tributárias efetivas medianas*

\begin{tabular}{lccccccccccc}
\hline & \multicolumn{1}{c}{ Décimos de trabalhadores ordenados pelo custo do trabalho } & \\
\cline { 2 - 10 } País & $\mathbf{1}$ & $\mathbf{2}$ & $\mathbf{3}$ & $\mathbf{4}$ & $\mathbf{5}$ & $\mathbf{6}$ & $\mathbf{7}$ & $\mathbf{8}$ & $\mathbf{9}$ & $\mathbf{1 0}$ & Todos \\
\hline Alemanha & 34,8 & 37,9 & 44,3 & 47,3 & 49,1 & 50,3 & 51,0 & 51,9 & 52,0 & 49,9 & 47,9 \\
Áustria & 32,3 & 34,4 & 38,2 & 40,4 & 42,1 & 43,0 & 44,4 & 45,5 & 47,7 & 47,9 & 42,4 \\
Bélgica & 39,5 & 45,7 & 49,4 & 51,3 & 52,1 & 53,6 & 55,7 & 55,6 & 56,8 & 59,7 & 52,3 \\
Brasil & $\mathbf{1 7 , 2}$ & $\mathbf{2 6 , 6}$ & $\mathbf{2 6 , 6}$ & $\mathbf{2 4 , 6}$ & $\mathbf{2 4 , 9}$ & $\mathbf{2 6 , 6}$ & $\mathbf{2 7 , 3}$ & $\mathbf{2 7 , 3}$ & $\mathbf{2 8 , 8}$ & $\mathbf{3 1 , 3}$ & $\mathbf{2 6 , 6}$ \\
Dinamarca & 39,1 & 41,3 & 43,3 & 44,2 & 44,9 & 44,0 & 44,1 & 44,8 & 46,2 & 49,4 & 43,8 \\
Espanha & 25,8 & 28,4 & 33,3 & 33,8 & 35,7 & 35,2 & 37,3 & 37,1 & 38,4 & 38,3 & 35,6 \\
\hline
\end{tabular}

continua...

13 A ocorrência de alguma carga associada ao IRPF para empregados com salários abaixo do nível de isenção é explicada pelo fato da base de cálculo do IRPF incluir outros tipos de rendimentos, além da renda do trabalho. Dessa forma, a renda tributável desses trabalhadores pode exceder o nível de isenção, ficando o trabalhador sujeito ao pagamento de imposto de renda, mesmo que marginalmente.

14 No caso do empregado doméstico, a alíquota de contribuição patronal para o INSS é de 12\% (em vez de $20 \%$ e não há outras contribuições patronais compulsórias. 
conclusão...

\section{Décimos de trabalhadores ordenados pelo custo do trabalho}

\begin{tabular}{lccccccccccc}
\cline { 2 - 8 } País & $\mathbf{1}$ & $\mathbf{2}$ & $\mathbf{3}$ & $\mathbf{4}$ & $\mathbf{5}$ & $\mathbf{6}$ & $\mathbf{7}$ & $\mathbf{8}$ & $\mathbf{9}$ & $\mathbf{1 0}$ & Todos \\
\hline Finlândia & 39,4 & 42,6 & 43,7 & 44,5 & 46,0 & 46,6 & 47,7 & 49,2 & 50,9 & 53,9 & 45,9 \\
França & 32,9 & 35,2 & 41,2 & 43,9 & 44,0 & 44,2 & 44,5 & 45,5 & 46,6 & 49,1 & 43,3 \\
Grécia & 0,6 & 36,0 & 36,0 & 36,3 & 36,6 & 36,6 & 37,2 & 38,2 & 39,2 & 42,2 & 36,6 \\
Holanda & 23,8 & 29,7 & 34,4 & 38,4 & 40,4 & 38,8 & 39,3 & 36,7 & 38,0 & 39,3 & 37,5 \\
Irlanda & 4,1 & 7,9 & 15,5 & 19,7 & 23,6 & 24,8 & 26,7 & 30,1 & 32,3 & 33,7 & 22,9 \\
Itália & 33,5 & 40,5 & 42,2 & 42,6 & 43,1 & 44,0 & 44,8 & 45,8 & 46,8 & 49,5 & 43,6 \\
Luxemburgo & 24,1 & 24,1 & 25,3 & 26,1 & 27,9 & 28,3 & 30,6 & 30,3 & 34,0 & 37,6 & 27,4 \\
Portugal & 28,1 & 28,6 & 30,5 & 31,6 & 32,4 & 32,6 & 33,9 & 34,7 & 37,9 & 45,5 & 32,5 \\
Reino Unido & 0,0 & 13,2 & 21,4 & 24,8 & 27,1 & 28,1 & 28,9 & 29,5 & 29,5 & 32,4 & 27,2 \\
\hline
\end{tabular}

Fonte: Immervoll (2004) e, para o Brasil, cálculo dos autores.

Nota: *No caso do Brasil, refere-se ao ano de 2009; para os demais países, 1998.

Pode-se verificar que a ordenação dos países pela carga tributária efetiva mediana sobre o trabalho pode ser bem diferente dependendo do grupo (décimo) de interesse, o que reflete uma dispersão significativa entre os diferentes grupos. Isso é confirmado no Gráfico 1, que ordena os países pela média geral da distribuição das alíquotas tributárias efetivas sobre o trabalho, mas indica também o desvio padrão e a mediana.

Gráfico 1 - Alíquotas tributárias efetivas sobre o trabalho*

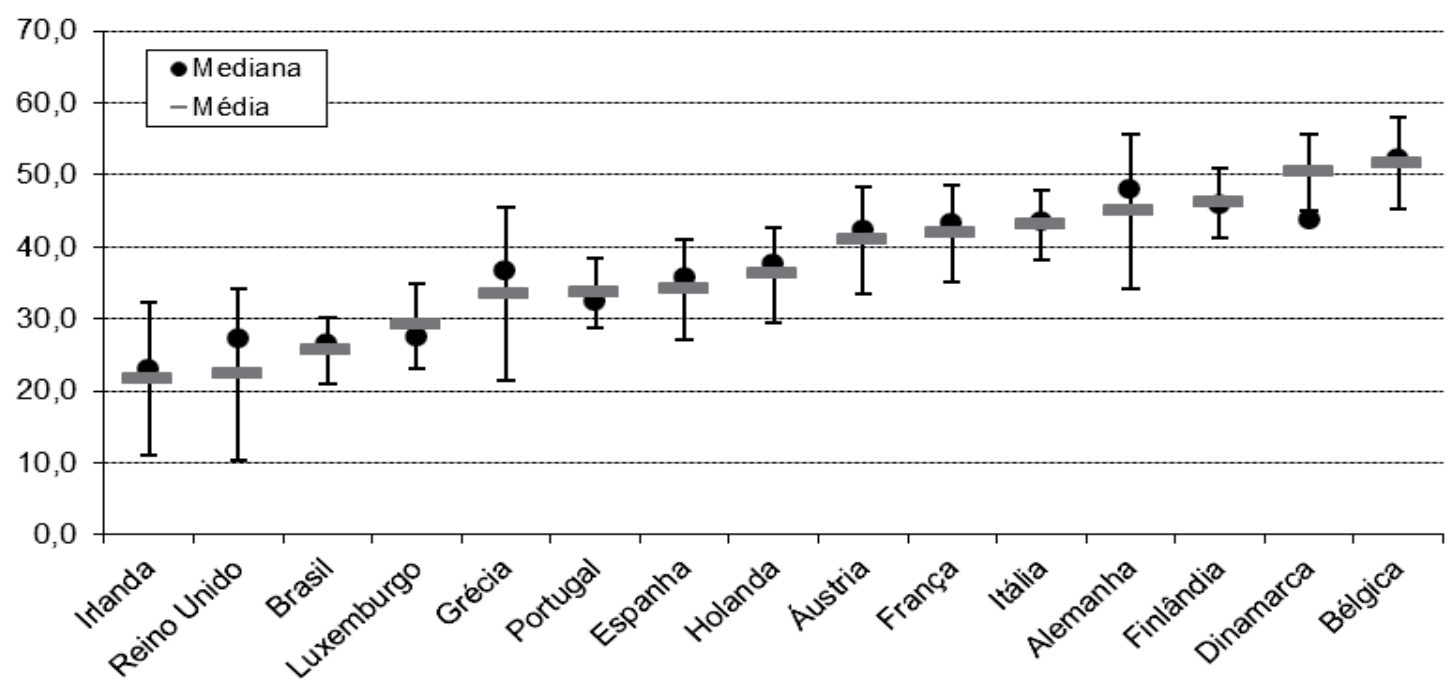

Fonte: Immervoll (2004) e, para o Brasil, cálculo dos autores.

Nota: "No caso do Brasil, refere-se ao ano de 2009; para os demais países, 1998. As barras verticais no gráfico mostram o desvio padrão.

No entanto, a posição do Brasil em relação aos outros países pouco depende do décimo considerado. Ordenando-se os países da maior para a menor carga 
tributária, na maioria das vezes, o Brasil fica em último ou penúltimo lugar entre os 15 países considerados. As exceções ocorrem nos casos do primeiro, segundo e terceiro décimos, em que o Brasil fica na $12^{\circ}$ posição. Olhando para as alíquotas efetivas medianas para todos os trabalhadores conjuntamente (todos os décimos), verificamos que o Brasil fica em penúltimo lugar, com a Irlanda em último.

Deve-se mencionar que os únicos benefícios governamentais considerados nos cálculos de Immervoll (2004) são do tipo créditos tributários recuperáveis (em inglês, refundable tax credits), presentes nos sistemas fiscais do Reino Unido e da Áustria. Esses créditos transformam-se em transferências monetárias para trabalhadores de baixa renda com determinadas características familiares. Todavia, mesmo que ignorássemos o salário família e o abono salarial no cálculo das alíquotas efetivas, a posição do Brasil em relação aos demais países da Tabela 4 não mudaria significativamente. Isso tem o efeito apenas de elevar as alíquotas tributárias efetivas medianas do quarto e do quinto décimos para $26,6 \%$, não sendo alteradas as alíquotas dos demais grupos.

Por fim, é interessante comparar a cunha fiscal sobre o trabalho no Brasil com as estimativas apresentadas no relatório anual da OCDE sobre a tributação de salários nos 34 países dessa organização (OCDE, 2011). As estimativas da OCDE não se baseiam em microdados. Em vez disso, a OCDE define oito "tipos" de trabalhadores e calcula, para cada um desses tipos, a cunha fiscal sobre o trabalho, aplicando as regras legais que definem as obrigações tributárias e o recebimento de benefícios monetários atrelados ao trabalho (pagos pelo governo). No presente estudo, a PNAD 2009 e o simulador BRAHMS foram utilizados para calcular a cunha fiscal média para quatro dos oito tipos de trabalhadores definidos pela OCDE. A Tabela 5 compara os resultados do Brasil com os da OCDE (2011). Cabe ressaltar que a definição de cunha fiscal sobre o trabalho no estudo da OCDE é a mesma que a usada no presente estudo.

Observa-se novamente que a carga tributária efetiva varia consideravelmente por tipo de trabalhador. Por exemplo, a alíquota tributária média dos países da OCDE é de 15,6\% para um trabalhador com dois filhos e salário igual a $67 \%$ do salário médio, e mais que o dobro disso $(39,6 \%)$ para um trabalhador sem filhos com salário igual a $167 \%$ do salário médio. Os percentuais correspondentes para o Brasil são de 22,3\% e 31,1\%, respectivamente.

Ordenando-se os 35 países (incluindo o Brasil) da maior para menor carga tributária sobre o trabalho, verifica-se que o Brasil ocupa a $26^{\circ}, 27^{\circ}$ e $29^{\circ}$ posições no caso do trabalhador sem filhos com salário igual a $67 \%, 100 \%$ e $167 \%$ do salário médio, respectivamente. ${ }^{15}$ Já no caso do trabalhador com dois filhos e com salário igual a $67 \%$ do salário médio, o Brasil apresenta a $14^{\circ}$ maior carga tributária entre

15 No Brasil, o salário médio da classe de trabalhadores definida como no estudo da OCDE (2011) era de $\mathrm{R} \$ 1.072,84 \mathrm{em} 2009$. 
os países da Tabela 5. Nota-se que para esse último tipo de trabalhador, a alíquota efetiva no Brasil (22,3\%) fica acima da média dos países da OCDE (15,6\%) e é quase igual à média dos países da União Europeia (21,5\%).

Tabela 5 - Cunha fiscal por tipo de família e nível salarial* - 2009 (\%)

\begin{tabular}{|c|c|c|c|c|}
\hline $\begin{array}{l}\text { Tipo de família } \\
\text { Nivel salarial (\% do salá- } \\
\text { rio médio) }\end{array}$ & $\begin{array}{c}\text { Sem filhos } \\
67\end{array}$ & $\begin{array}{l}\text { Sem filhos } \\
100\end{array}$ & $\begin{array}{c}\text { Sem filhos } \\
167\end{array}$ & $\begin{array}{c}\text { Com dois filhos** } \\
67\end{array}$ \\
\hline Alemanha & 46,0 & 50,9 & 53,0 & 31,3 \\
\hline Austrália & 19,7 & 26,2 & 31,9 & $-11,7$ \\
\hline Áustria & 43,2 & 47,8 & 50,2 & 26,2 \\
\hline Bélgica & 49,4 & 55,4 & 60,6 & 34,7 \\
\hline Canadá & 26,1 & 30,6 & 31,6 & $-8,9$ \\
\hline Chile & 7,0 & 7,0 & 7,0 & 3,2 \\
\hline Coreia & 16,9 & 19,3 & 21,8 & 16,3 \\
\hline Dinamarca & 38,0 & 39,5 & 48,5 & 12,9 \\
\hline Eslovênia & 39,7 & 42,2 & 47,1 & 12,3 \\
\hline Espanha & 34,3 & 38,3 & 41,6 & 27,9 \\
\hline Estados Unidos & 27,3 & 29,6 & 35,0 & 4,8 \\
\hline Estônia & 37,7 & 39,2 & 40,3 & 22,6 \\
\hline Finlândia & 36,9 & 42,3 & 48,1 & 25,2 \\
\hline França & 45,1 & 49,2 & 53,1 & 36,7 \\
\hline Grécia & 34,4 & 38,2 & 43,2 & 34,4 \\
\hline Holanda & 33,2 & 38,0 & 41,8 & 11,0 \\
\hline Hungria & 46,2 & 53,1 & 58,3 & 29,6 \\
\hline Irlanda & 22,7 & 29,0 & 39,3 & $-8,3$ \\
\hline Islândia & 22,2 & 28,0 & 32,6 & 3,8 \\
\hline Israel & 13,3 & 20,2 & 29,0 & 0,8 \\
\hline Itália & 43,5 & 46,8 & 52,1 & 27,0 \\
\hline Japão & 27,7 & 29,1 & 32,3 & 21,4 \\
\hline Luxemburgo & 27,3 & 33,8 & 41,3 & 0,2 \\
\hline México & 11,9 & 15,3 & 20,9 & 11,9 \\
\hline Noruega & 33,7 & 36,9 & 42,6 & 19,8 \\
\hline Nova Zelândia & 15,4 & 17,7 & 24,2 & $-18,2$ \\
\hline Polônia & 33,2 & 34,2 & 34,9 & 28,4 \\
\hline Portugal & 32,7 & 37,5 & 43,3 & 21,3 \\
\hline Reino Unido & 29,3 & 32,5 & 37,1 & 9,2 \\
\hline República da Eslováquia & 34,4 & 37,7 & 40,1 & 21,5 \\
\hline República Tcheca & 38,7 & 42,0 & 44,6 & 15,4 \\
\hline Suécia & 41,3 & 43,2 & 51,1 & 33,0 \\
\hline Suíça & 17,8 & 20,8 & 25,0 & 2,4 \\
\hline Turquia & 35,0 & 37,4 & 40,1 & 33,7 \\
\hline
\end{tabular}


conclusão...

\begin{tabular}{lcccc}
\hline $\begin{array}{l}\text { Tipo de família } \\
\text { Nivel salarial (\% do salá- } \\
\text { rio médio) }\end{array}$ & $\begin{array}{c}\text { Sem filhos } \\
\mathbf{6 7}\end{array}$ & $\begin{array}{c}\text { Sem filhos } \\
\mathbf{1 0 0}\end{array}$ & $\begin{array}{c}\text { Sem filhos } \\
\mathbf{1 6 7}\end{array}$ & $\begin{array}{c}\text { Com dois filhos** } \\
\mathbf{6 7}\end{array}$ \\
\hline $\begin{array}{l}\text { Média não ponderada } \\
\text { OCDE }\end{array}$ & 31,2 & 35,0 & & \\
União Europeia (15 países) & 37,2 & 41,5 & 47,6 & 15,6 \\
União Europeia (21 países) & 37,5 & 41,5 & 46,2 & 21,5 \\
Brasil & $\mathbf{2 5 , 2}$ & $\mathbf{2 8 , 5}$ & $\mathbf{3 1 , 1}$ & 21,5 \\
\hline
\end{tabular}

Fonte: OCDE (2011) e, para o Brasil, cálculo dos autores.

Nota: * Cunha fiscal (imposto de renda mais contribuições do empregado e do empregador menos benefícios monetários) como percentagem do custo do trabalho. ** Sem cônjuge.

\section{Considerações Finais}

Este artigo analisa o nível, a distribuição e a estrutura da cunha fiscal sobre o trabalho no Brasil, mostrando quantos e que tipos de trabalhadores são afetados por diferentes níveis de carga tributária. Os resultados mostram que a cunha fiscal média representa em torno de um quarto do custo total do trabalho, porém, há variações significativas entre subgrupos de trabalhadores. Por exemplo, a alíquota tributária efetiva para um trabalhador que recebe um salário mínimo e tem três ou mais filhos é igual a pouco mais de um terço da alíquota para um trabalhador com rendimento acima de 30 salários mínimos.

O estudo mostra também que, comparada às cunhas fiscais dos países da União Europeia e da OCDE, a carga brasileira é uma das mais baixas, principalmente para as classes salariais mais altas. Esse resultado deve ser considerado tendo em mente o seguinte:

a) a carga tributária total no Brasil (36\% do PIB) é próxima da carga média da OCDE (38\% do PIB); e

b) o gasto público com previdência social no Brasil (11,8\% do PIB) é mais elevado do que o gasto médio dos países da $\operatorname{OCDE~}(9,5 \%$ do PIB) e da Europa Ocidental (10,9\%). ${ }^{16}$

Portanto, controlando para esses fatores, a cunha fiscal sobre o trabalho no Brasil (composta essencialmente de contribuições previdenciárias) não é particularmente elevada.

16 Ver Rocha e Caetano (2008). 


\section{Referências}

ARAÚJO NETO, V. B.; SOUSA, M. C. S. Tributação da renda e do consumo no Brasil: uma abordagem macroeconômica. Estudos Econômicos, São Paulo, v. 33, n. 1, p. 5-42, 2003.

BRASIL. Ministério da Fazenda. Reforma tributária. Brasília, 2008. Disponível em: <http:// www.fazenda.gov.br/portugues/documentos/2008/fevereiro/Cartilha-Reforma-Tributaria. pdf $>$. Acesso em: 12 fev. 2012.

. Secretaria da Receita Federal. Consolidação da Declaração do Imposto de Renda das Pessoas Físicas: 2004, Brasília, 2008. Disponível em: <http://www.receita.fazenda.gov. br/Publico/estudotributarios/estatisticas/ConsolidaDirpf2004.pdf> . Acesso em: 12 fev. 2012.

CLARK, W. S. Using micro data to assess average tax rates. In: SORENSEN, P. B. (Ed.). Measuring the Tax Burden on Capital and Labor. Cambridge: MIT Press, 2004. (CESifo Seminar Series).

DEPARTAMENTO INTERSINDICAL DE ESTATÍSTICA E ESTUDOS SOCIOECONÔMICOS - DIEESE. Encargos sociais no Brasil: conceito, magnitude e reflexos no emprego. São Paulo, 1997.

FERNANDES, R.; MENEZES-FILHO, N. A. Impactos dos encargos trabalhistas sobre o setor formal da economia. In: CHAHAD, J. P.; FERNANDES, Z. R. (Org.). O mercado de trabalho no Brasil: políticas, resultados e desafios. São Paulo: FIPE, 2002. Vol. 1.

HEADY, C. The 'Taxing Wages' approach to measuring the tax burden on labor. In: SORENSEN, P. B. (Ed.). Measuring the Tax Burden on Capital and Labor. Cambridge: MIT Press, 2004. (CESifo Seminar Series).

IMMERVOLL, H. Average and marginal effective tax rates facing workers in the EU: a microlevel analysis of levels, distribution, and driving factors. OECD Social, Employment and Migration Working Papers, Paris, v. 19, p. 2-43, 2004.

IMMERVOLL, H. et al. Simulating the Brazilian tax-benefit system using BRAHMS, the Brazilian household micro-simulation model. Economia Aplicada, Ribeirão Preto, v. 10, n. 2, Apr./ Jun. 2006.

The impact of Brazil's tax-benefit system on inequality and poverty. In: KLASEN, S.; NOWAK-LEHMANN, F. (Ed.). Poverty, Inequality, and Policy in Latin America. Cambridge: MIT Press, 2008. (CESifo Seminar Series).

INSTITUTO BRASILEIRO DE PLANEJAMENTO TRIBUTÁRIO - IBPT. Carga tributária sobre salários. Curitiba, 2006.

LEVY, $\mathrm{H}$. et al. Simulating the impact of inflation on the progressivity of personal income tax in Brazil. Revista Brasileira de Economia, Rio de Janeiro, v. 64, n. 4, out./dez. 2010.

ORGANIZAÇÃO PARA A COOPERAÇÃO E DESENVOLVIMENTO ECONÓMICO - OCDE. Taxing Wages 2009/2010. Paris, 2011.

PAES, N. L.; BUGARIN, M. N. Parâmetros tributários da economia brasileira. Estudos Econômicos, São Paulo, v. 36, n. 4, out./dez. 2006.

ROCHA, R. R.; CAETANO, M. A. O sistema previdenciário brasileiro: uma avaliação de desempenho comparada. Brasília: IPEA, 2008. (Texto para discussão, n. 1331).

Recebido em: 14/09/2012.

Aceito em: 05/11/2012. 